\title{
Health technology assessment: the journey continues
}

\author{
Devidas Menon PhD
}

$\mathrm{P}$ errin Beatty, Canadian minister of health and welfare, 1989-1991, said that Canada needs "a more coordinated approach across the country to ensure that all Canadians are benefiting from the advances being made in health technology." These words marked the creation of the Canadian Coordinating Office for Health Technology Assessment (CCOHTA). How far has health technology assessment come in Canada since then, and what challenges are ahead?

Canada has deep roots in the field of evidence and health. The Canadian Task Force on the Periodic Health Examination was created in 1976. McMaster University in Hamilton, Ont., led the earliest developments in evidence-based medicine. Health technology assessment was therefore a natural extension of the production and use of evidence in system-level decision-making. However, the challenges were substantial.

First, CCOHTA was established in 1989 by the federal, provincial and territorial governments with the primary mandate of "coordinating." This was challenging; Quebec had established a health technology assessment organization (now known as l'Institut national d'excellence en santé et en services sociaux, or INESSS), British Columbia would soon establish the BC Office of Health Technology Assessment, and Alberta had built capacity for health technology assessment within its health ministry. But the remaining jurisdictions relied on CCOHTA. Thus, CCOHTA had a dual role: coordinating information and being a producer of health technology assessment for jurisdictions lacking built-in systems.

Second was the issue of academic and scientific credibility. CCOHTA's $\$ 500000$ annual budget limited its ability to acquire talent for specific projects. It took the goodwill of many academic experts to elevate CCOHTA to a level where it could be respected and accepted by both academics and policy-makers.

The subsequent 25 years have seen many developments in Canadian health technology assessment. In the early 21 st century, CCOHTA became the Canadian Agency for Drugs and Technologies in Health (CADTH) and received a substantial funding increase, following recommendations from the Romanow Commission and the Senate Standing Committee on Social
Affairs, Science and Technology, more popularly known as the Kirby Committee., ${ }^{1,2}$ But some provinces continued to increase investment in their health technology assessment programs, creating a fork in the road, with drug-related health technology assessment taking a different path from other health technology assessment.

Ten years ago, Canada's balkanized system of drug review processes became more systematic and consistent. CADTH now manages the Common Drug Review and the pan-Canadian Oncology Drug Review. CADTH also provides many other services and products, some of which deal with nondrug issues.

However, the more substantial investment in nondrug health technology assessment has come from some provincial governments. Alberta established the Alberta Health Technologies Decision Process, ${ }^{3}$ Health Quality Ontario runs a provincial evaluation program, ${ }^{4}$ and INESSS manages health technology assessment for Quebec. These processes are formally linked to governments' decision-making about new nondrug technologies.

The final set of players emerging in recent years comprises hospitals and health authorities. In Quebec and Ontario, in particular, hospitalbased health technology assessment units have been created to help hospital administration with acquisition decisions.

So, what does health technology assessment face in Canada now? At least four challenges exist.

First, how should the value of a technology be defined? Who should define it? The qualityadjusted life-year and incremental cost-effective-

\section{KEY POINTS}

- Canada has had institutionalized health technology assessment for a quarter of a century.

- Over this period, health technology assessment has developed and is now an important part of decision-making by governments across the country.

- CADTH has responsibility for overseeing the centralized review of all new drugs that are being considered by participating public drug plans.

- Challenges for the future of health technology assessment in Canada include understanding and defining the value of a health technology; more meaningful involvement of patients in health technology assessment and decision-making processes; dealing with a fragmented system of health technology assessment for nondrug technologies; and addressing companion diagnostics and personalized medicine. 
ness ratio have become part of the language of health technology assessment in Canada, but these metrics may not truly measure what society considers the real value of a particular health technology. This is clear, for example, in the area of rare, untreated diseases, where new treatments are extremely expensive. Methodologists, producers and policy-makers involved in health technology assessment (who explicitly or implicitly use decision-making "thresholds") will need to come to grips with this issue. This will require a broader perspective on how we measure value.

Second, health technology assessment in Canada has made substantial progress in engaging physicians, but patient involvement and participation have been limited. There is some degree of patient involvement and some patient membership on committees, both those overseeing health technology assessment and those making funding recommendations. Unfortunately, there are still many influential people involved in health technology assessment and resource allocation who believe that a patient would bring a biased perspective to deliberations that are meant to be rational and science-based. However, decisions are value-laden, and one could ask whether a patient is any more biased than a clinician-scientist who has been involved in industry-sponsored clinical trials.

Third, nondrug health technology assessment occurs differently across jurisdictions. In part, this is a result of decision-making in this area being much more decentralized than it is with drugs; it is often not clear how decisions are made or by whom. But the question remains whether a more centralized approach to evidence review of new nondrug technologies is needed, or even desired. The Common Drug Review and the pan-Canadian Oncology Drug Review can claim to have achieved efficiencies in evidence review; is the same feasible for other technologies?

Fourth, a potential challenge exists with companion diagnostics and personalized medicine.
There is concern across jurisdictions about diagnostic tests used to select patients for specific targeted treatments. Assessment of test-treatment combinations is needed, and this will challenge both the regulatory processes of Health Canada and the funding decisions of the provinces and territories. For CADTH and the governments that fund it, role definition will become important. Are the processes that have evolved for the assessment of drugs and nondrug technologies fit for companion diagnostics, given that there will be a combined test and (most often) a drug to assess? Whose responsibility would it be to ensure that good methodological guidance is available for companion diagnostics? Provincial governments, which typically deal with drug funding and funding of other technology-based services separately, will need to increase coordination within their health ministries.

The health technology assessment journey in Canada continues. Health technology assessment has become a staple in informing funding decisions at various levels. The future could be very bright, and the next 25 years could be even more productive. It will require the increased and genuine engagement of all stakeholders if Canadians are to truly benefit from advances in health technology, as Mr. Beatty suggested 25 years ago.

\section{References}

1. Building on values: the future of health care in Canada. Ottawa $(\mathrm{ON})$ : Commission on the Future of Health Care in Canada; 2002. Available: www.publications.gc.ca/collections/Collection /CP32-85-2002E.pdf (accessed 2014 Aug. 7).

2. Senate Standing Committee on Social Affairs, Science and Technology. 2002. The health of Canadians - the federal role. Final report. Available: www.parl.gc.ca/content/sen/committee 1372/soci/rep/repoct02vol6-e.htm (accessed 2014 Aug. 7).

3. Borowski HZ, Brehaut J, Hailey D. Linking evidence from HTAs to policy and decision making: the Alberta Model. Int $J$ Technol Assess Health Care 2007;23:155-61.

4. Evidence process. Toronto (ON): Health Quality Ontario; 2013. Available: www.hqontario.ca/evidence (accessed 2014 Aug. 7).

Affiliation: School of Public Health, University of Alberta, Edmonton, Alta. 